\title{
Um Sistema de Informação para Melhoramento Genético de Caprinos e Ovinos
}

\author{
Alternative Title: An Information System for Genetic Improvement of Goats and \\ Sheep
}

\author{
Thasciano Carvalho \\ UFPI, Teresina, Piauí, Brazil \\ thasciano@gmail.com \\ Pedro Almir Oliveira \\ IFMA, Pedreiras, Maranhão, \\ Brazil \\ petrus.cc@gmail.com
}

\author{
Natanael Santos \\ UFPI, Teresina, Piauí, Brazil \\ natanaelpss@gmail.com \\ Pedro Santos Neto \\ UFPI/Infoway, Teresina, Piauí, \\ Brazil \\ pasn@ufpi.edu.br, \\ pasn@infoway-pi.com.br \\ Ricardo Rabêlo \\ UFPI, Teresina, Piauí, Brazil \\ ricardoalr@ufpi.edu.br
}

\author{
Werney Lira \\ UFPI, Teresina, Piauí, Brazil \\ werney.zero@gmail.com \\ José Lindenberg \\ Sarmento \\ UFPI, Teresina, Piauí, Brazil \\ sarmento@ufpi.edu.br
}

\begin{abstract}
RESUMO
Este trabalho descreve um sistema de informação para melhoramento genético de caprinos e ovinos, com o objetivo de maximizar o ganho de peso e minimizar o grau de parentesco do rebanho. O melhoramento genético foi desenvolvido com base na literatura da ciência animal e implementado a partir do uso de algoritmos de inteligência computacional. O sistema foi aplicado em um projeto piloto, com poucos animais, para avaliação dos resultados e, devido ao seu sucesso, está sendo usado em caráter experimental em um rebanho de uma instituição de ensino superior com cerca de 200 animais. A partir do seu uso é possível predizer os melhores casais para acasalar, de forma a potencializar o ganho de peso das futuras gerações, minimizando o grau de parentesco do rebanho.
\end{abstract}

\section{Palavras-Chave}

Sistema de Informação, inteligência Computacional, Melhoramento Genético.

\begin{abstract}
This work describes an information system created to genetical enhancement of sheep and goats, with the goal to maximize weight gain and minimize the degree of kinship of the herd. The genetic enhancement was developed using animal science literature and implemented by using compu-
\end{abstract}

Permission to make digital or hard copies of all or part of this work for personal or classroom use is granted without fee provided that copies are not made or distributed for profit or commercial advantage and that copies bear this notice and the full citation on the first page. To copy otherwise, to republish, to post on servers or to redistribute to lists, requires prior specific permission and/or a fee.

SBSI 2016, May 17th-20th, 2016, Florianópolis, Santa Catarina, Brazil Copyright SBC 2016. tational intelligence algorithms. The system was applied in a pilot project, with few animals, in order to evaluate the results. The observed result was considered a success, so, the information system is being used in an experimental purpose in a higher education institution. From its use is possible to predict the best couples to mate in order to generate better descendants in terms of weight gain minimizing the degree of kinship of the herd for future generations.

\section{Categories and Subject Descriptors}

H.4 [Information Systems Applications]: Miscellaneous; D.2.8 [Software Engineering]: Metrics - complexity measures, performance measures

\section{General Terms}

Theory

\section{Keywords}

Information System, Computational Intelligence, Genetical Enhancement.

\section{INTRODUÇÃO}

Os ovinos e caprinos são os pequenos ruminantes que mais são explorados economicamente em todos os países. No entanto, somente em poucos países a atividade da ovinocaprinocultura demonstra grande expressão econômica, geralmente associada ao uso de raças especializadas e tecnologias avançadas. Na maioria dos casos, as criações desses animais são desenvolvidas de forma extensiva e com baixa tecnologia, com reduzida produtividade e rentabilidade [24].

A ovinocaprinocultura tem se destacado no agronegócio brasileiro. No Brasil existem aproximadamente 26 milhões de cabeças, sendo 8,7 milhões de caprinos e 17,3 milhões de ovinos. No Nordeste é onde mais se explora caprinos e ovinos, contando com 8 milhões de caprinos e 9,7 milhões 
de ovinos [12]. Carne, pele e lã estão entre os principais produtos associados a essa atividade. A demanda por esses produtos torna-se cada vez mais visada pelo mercado consumidor, gerando a busca pela produção e processamento de alimentos mais elaborados e com certificado de qualidade [20].

Apesar do potencial brasileiro para a produção de carne e leite, ainda não é possível atender as necessidades internas. Isto é causado pelo ineficiente sistema de produção, com o abate dos animais em idade avançada, e do baixo valor genético desses animais. A caprino e ovinocultura no Nordeste têm apresentado formas que as colocam numa posição estratégica no cenário do agronegócio, respaldado no incremento do consumo interno de carne, leite e da demanda dos curtumes por peles de qualidade. No entanto, é necessário melhorar a qualidade do que é produzido nesse setor [19].

Uma forma de se incrementar o nível de qualidade de um rebanho se dá pelo uso de técnicas de melhoramento genético. O melhoramento genético animal é baseado na seleção de indivíduos com fenótipos desejáveis como pais para a próxima geração. Essa técnica necessita de um bom controle dos rebanhos e aplicações de fórmulas matemáticas para analise genética [9].

A técnica de melhoramento genético foi proposta há muito tempo mas não é utilizada no dia-a-dia de uma fazenda de um pequeno criador, pois é grande a quantidade de cálculos, ajustes e agrupamentos que o criador deve fazer. Até mesmo para um especialista em Ciência Animal é necessário uso de manipulação de dados em planilhas eletrônica e com fórmulas bastante complexas, além de manter um completo controle zootécnico do rebanho, com informações variadas sobre peso, tamanho, pais e parentesco, tornando esse controle muito difícil sem o apoio de um sistema de informação.

Este trabalho apresenta justamente um sistema de informação para controle zootécnico de rebanhos de caprinos e ovinos, disponível na Web sob a forma de um serviço em nuvem. O sistema, além de controlar um rebanho, possui implementado uma função para apoiar o melhoramento genético a partir da sugestão de acasalamentos, utilizando uma técnica de Inteligência Computacional associada à teoria de melhoramento genético. Tal sistema está em uso no rebanho de uma instituição federal de ensino superior e pretendese disponibilizá-lo como um serviço aberto e gratuito para pequenos criadores, fomentando assim o crescimento desse arranjo produtivo tão importante para o Brasil

De forma resumida, o uso do sistema por parte de um criador de ovinos e caprinos permite o obtenção das seguintes vantagens:

- Melhora na qualidade genética do rebanho;

- Aumento da variabilidade genética do rebanho;

- Redução de gastos com a contratação de especialistas.

O restante deste trabalho está assim organizado: a Seção 2 apresenta a fundamentação teórica para este trabalho; a Seção 3 apresenta alguns trabalhos relacionados; a Seção 4 apresenta a abordagem para melhoramento genético implementada no CAPRIOVI; a Seção 5 descreve um estudo de caso realizado com tal abordagem; e, finalmente, na Seção 6 são apresentadas as conclusões e direções para trabalhos futuros.

\section{FUNDAMENTAÇÃO TEÓRICA}

\subsection{CAPRIOVI}

O CAPRIOVI (Figura 1) é um sistema de informação para gestão de rebanhos de uma fazenda, permitindo realizar a escrituração zootécnica, que basicamente consiste no registro de todos os eventos que ocorrem no rebanho, sistematicamente. De forma mais detalhada, pode-se descrever a escrituração zootécnica como sendo a realização de anotações de controle de um determinado rebanho, com fichas individuais e coletivas, registrando dados referentes à genealogia, ocorrência do desempenho produtivo e reprodutivo. São exemplos de tais dados: os nascimentos, as coberturas, as enfermidades, morte, descartes, procedimentos realizados, pesagens, medidas morfométricas (altura, circunferência escrotal e presença de cornos) [21].

A escrituração zootécnica permite tanto o controle zootécnico quanto genético, tornando possível gerar relatórios genéticos, zootécnicos de produção e zootécnicos de reprodução.

O CAPRIOVI foi desenvolvido em 2011 para fins de automação da escrituração zootécnica de um rebanho. Porém, com as informações existentes em seus registros foi possível introduzir técnicas de melhoramento genético, apoiando a criação de caprinos e ovinos de forma diferenciada. Usualmente, esse tipo de criação é muito baseada em pequenos criadores, com pequenos rebanhos.

Neste trabalho apresenta-se a evolução no CAPRIOVI no que se refere à introdução de uma técnica de melhoramento genético, que visa propor os melhores acasalamentos intrarebanhos. No entanto, a quantidade de combinações a serem analisadas para um rebanho pequeno (200 animais, por exemplo) é muito grande, sendo normalmente a quantidade de machos mais um elevado à quantidade de fêmeas. A análise dessas combinações possui um alto custo computacional e requer bastante tempo de processamento. Dessa forma, é necessário o uso de algoritmos de Inteligência Computacional de forma que essas técnicas sejam aplicadas em um tempo hábil para os usuários do sistema.

\subsection{Melhoramento Genético}

Melhoramento genético é o conjunto de técnicas que visam aumentar a frequência de genes desejáveis ou combinações genéticas boas em uma população. Ele tem o objetivo de melhoria e/ou fixação de alguma característica importante. Características genéticas constituem elementos básicos para que orientem o melhoramento genético dos animais. A importância econômica de um animal é medida por um conjunto de características e que normalmente estão correlacionadas. Assim, a seleção para uma ou duas pode alterar indiretamente outras características importantes, o que requer a necessidade de estudá-las conjuntamente [8].

Um aspecto importante para o melhoramento genético é a seleção do grupo para o acasalamento. A seleção é o processo decisivo que indica quais animais de uma geração se tornarão pais da próxima. Isso tem impacto direto no processo de melhoria, uma vez que o acasalamento entre indivíduos aparentados normalmente tende a reduzir a variabilidade e limitar o processo genético ao longo das gerações, o que pode contribuir para diminuir a qualidade do rebanho.

Nas próximas subseções apresentam-se diversas características que devem ser levadas em consideração na realização do melhoramento genético.

\subsubsection{Peso}




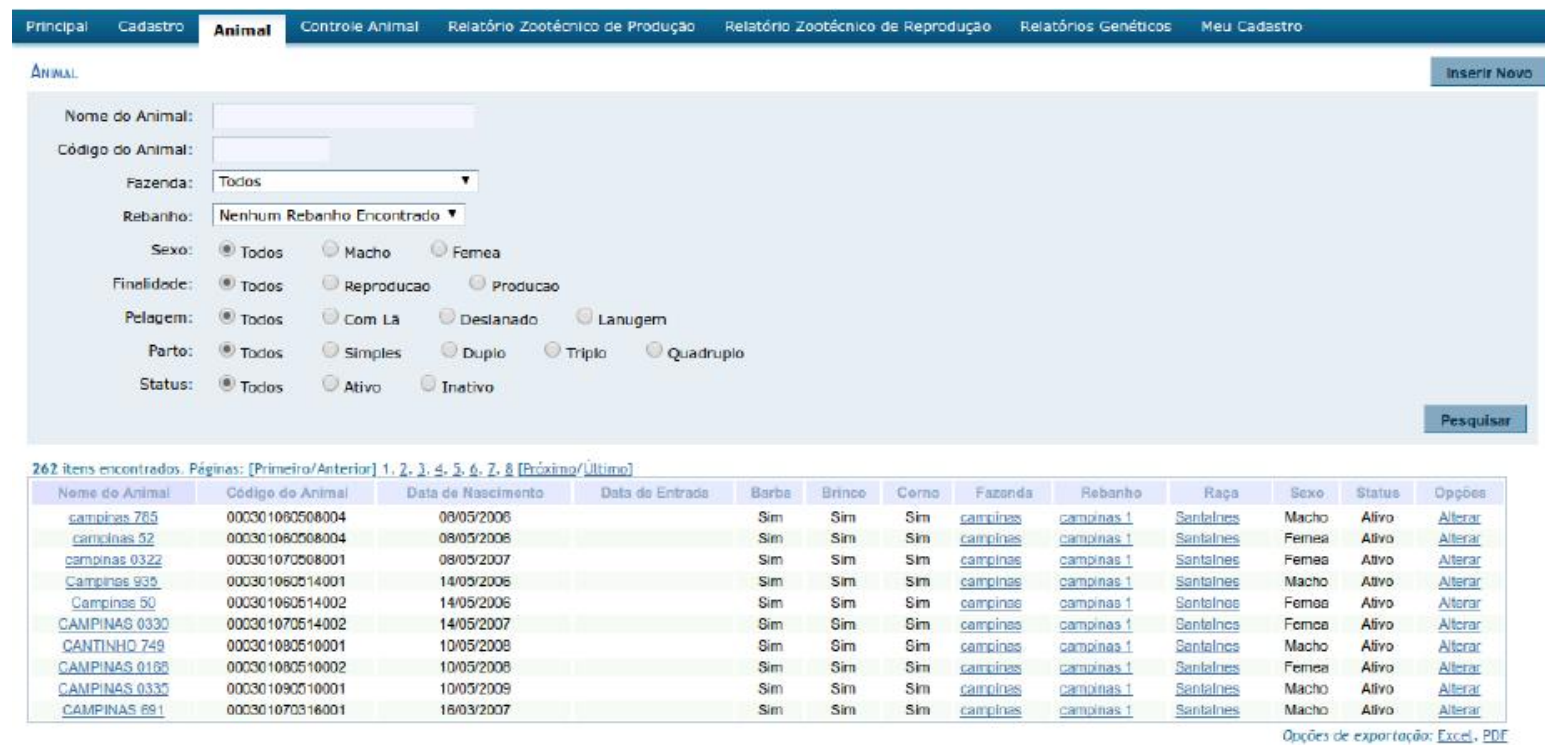

Figura 1: Lista de animais cadastrados no CAPRIOVI

O peso é uma das características que podem ser melhoradas geneticamente em um rebanho. Ele é a característica avaliada neste trabalho. O peso em um rebanho deve ser coletado para cada animal, em diferentes datas. Para que sejam feitos os cálculos de forma correta é necessário que os pesos sejam ajustados, assim todos os animais podem ser avaliados de forma padronizada.

A projeção do peso é dada como sendo a média de ganho de peso diário vezes a quantidade de dias da projeção.

$$
\text { Peso }=\frac{p_{i}}{t_{i}} * t_{\text {proj }}
$$

Onde:

- $p_{i}$ : Valor da última pesagem após a pesagem ao nascer;

- $t_{i}$ : Quantidade de dias da data de nascimento até a data da última pesagem após a pesagem ao nascer;

- $t_{\text {proj }}$ : Quantidade de dias para a qual será projetado o peso.

\subsubsection{Diferencial Esperado de Progênie}

O Diferencial Esperado de Progênie (DEP) é uma previsão da capacidade de transmissão de características de um animal. Usado para comparar animais dentro de uma raça quanto ao desempenho de suas futuras progênies [1].

Para que seja possível comparar e gerar DEPs é necessário separar os animais em Grupos de Contemporâneos (GC), que é um conjunto de animais agrupados em condições semelhantes. A razão pela qual a formação desses grupos é importante é que as diferenças entre animais que foram tratados ou criados de maneira semelhante fornecem informações puras, não contaminadas, sobre as verdadeiras diferenças genéticas entre os animais.

As características para seleção e divisão em grupos de contemporâneos será definida pelo criador podendo ser: por ano, sexo e estação de nascimento do animal. O sexo do animal sempre será uma variável para diferença entre grupos, pois o sexo tem influência em certas características a serem observadas, por exemplo o peso. Estes grupos são necessários para calcular a diferença esperada de progênies para cada animal.

A fórmula para calcular o Diferencial Esperado de Progênie para peso é dada pela fórmula:

$$
D E P=\frac{\left(p-\overline{p_{g c}}\right) * h^{2}}{2}
$$

Onde:

- $\overline{p_{g c}}$ : É a média dos pesos do grupo contemporâneo a que o animal pertence;

- p : É o peso do animal;

- $h^{2}$ : É a herdabilidade da característica, definida pelo criador com base na literatura.

\subsubsection{Endogamia}

A endogamia é a resultante do acasalamento de animais aparentados. Muitos criadores a tem usado com o objetivo de assegurar uniformidade racial e fixação de certas características, porém seu uso é incerto pois a chance de nascer um animal muito bom ou de nascer um animal muito ruim é de $50 \%$. A endogamia acima de certos níveis tem sido registrada como deterioradora do rebanho, do vigor e do crescimento dos animais, ocasionando ainda diminuição no desempenho reprodutivo $[16,14,17,22]$.

A Matriz de Parentesco expressa a semelhança genética entre os animais incluídos na avaliação, ou seja, mede a covariância entre as observações dos animais a partir do cálculo de uma semelhança genética esperada. O uso da matriz de parentesco deve melhorar a precisão das estimativas dos valores genéticos e quase sempre aumenta a correlação entre os valores genéticos dos indivíduos aparentados [4].

Para se predizer valores genéticos (matriz de parentesco) exige-se o cálculo da matriz inversa de "A" (a matriz dos 
coeficientes de parentesco entre os animais). Henderson desenvolveu regras simples para o cálculo dos elementos da inversa de "A", a partir de uma lista de animais com pais e mães correspondentes [11]. Quaas expandiu as regras de Henderson para incluir coeficientes de parentesco [18].

Um exemplo da matriz resultante dos animais representados na Tabela 1 (Seção 5) é apresentado na Figura 2. A matriz gerada é quadrada e cada valor está correlacionado ao grau de parentesco que o animal correspondente da linha tem em relação ao animal correspondente da coluna. Ilustrando a partir de um exemplo: o valor da posição $[2,1]=$ $(0,5)$ expressa a correlação entre o animais 2 e 1 , ou seja, o animal 2 tem $50 \%$ de parentesco com o animal 1 . Os valores correspondentes da diagonal principal expressam o grau de parentesco com os antepassados, por exemplo: o valor da posição $[1,1]=(1)$ expressa que o animal 1 não tem parentesco com os antepassados, mas o valor da posição $[4,4]=$ $(1,25)$ expressa que o animal 4 tem uma endogamia de 0,25 ou $25 \%$.

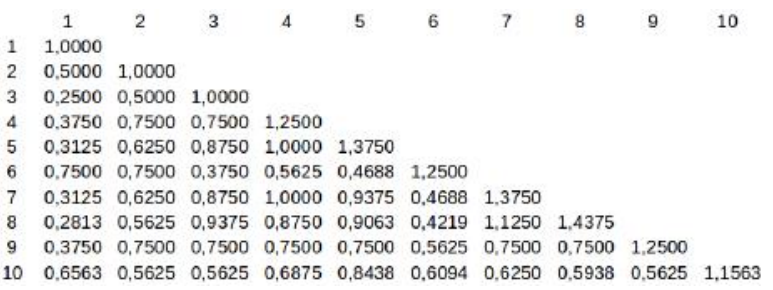

\section{Figura 2: Matriz de parentesco do rebanho}

Para predizer o grau de parentesco de um novo descendente em relação ao rebanho, deve-se usar a seguinte fórmula:

$$
\text { End }=1+\frac{M_{[i, j]}}{2}
$$

Onde $M_{[i, j]}$ é o valor do parentesco do casal.

\subsubsection{Ganho Genético Médio do Rebanho}

O Ganho Genético é definido como a superioridade da população melhorada em relação à população não melhorada. Dessa forma, a média genotípica da população melhorada corresponde à média dos valores genéticos dos indivíduos selecionados, ao passo que a média da população não melhorada corresponderá à média dos valores genéticos de todos os indivíduos da população.

O ganho genético pode ser decomposto na seguinte equação:

$$
\Delta G=\frac{\overline{i_{m}}+\overline{i_{f}}}{\overline{l_{m}}+\overline{l_{f}}} * h^{2} * \sigma_{p}
$$

- Média das intensidades de seleção $\overline{i_{m}}$ e $\overline{i_{f}}$ : é a predição da superioridade do grupo selecionado (em unidades de desvio padrão) em relação aos animais considerados para a seleção;

- Média dos intervalos entre gerações $\overline{l_{m}}$ e $\overline{l_{f}}$ : é definida como a média de idade dos pais quando sua progênie nasce, ou seja, é a média de idade em que o animal foi pai;
- $h^{2}$ : herdabilidade da característica avaliada;

- $\sigma_{p}$ : é calculado com base na característica que se quer levar para a próxima geração (peso).

No geral, as intensidades de seleção para machos são maiores devido a sua maior taxa reprodutiva, necessitando menos machos para reprodução.

\subsection{Algoritmos Genéticos}

Algoritmos Genéticos (AGs) são algoritmos de busca baseados em alguns dos processos de evolução natural como: cruzamento, mutação e a seleção natural [10]. A partir desses processos o AG realiza uma otimização no espaço de busca do problema, dirigindo-se para as regiões promissoras.

Diferente de outros algoritmos de otimização, AGs conseguem equilibrar duas tarefas básicas, o exploitation e o exploration. Exploitation corresponde à capacidade de aproveitar as soluções já adquiridas, enquanto o exploration indica a capacidade de explorar novas soluções no espaço de busca. O processo de busca/otimização preserva soluções candidatas e provoca a troca de informação entre as soluções exploradas [15].

Um AG começa gerando um conjunto de soluções candidatas para o problema, definida como população inicial, em seguida é atribuído um fitness a cada um dos indivíduos por meio de uma função de avaliação. Seguindo o princípio de Darwin, indivíduos superiores aos seus concorrentes obtêm uma melhor chance para promover os seus genes à geração seguinte por meio de um método de seleção.

Operadores genéticos tais como recombinação e mutação são aplicados aos pais selecionados, a fim de gerar uma nova população para o problema, se o critério de parada não for atendido o ciclo volta para o passo de seleção, até este critério ser alcançado [7]. A Figura 3 representa o ciclo da implementação de um algoritmo genético.

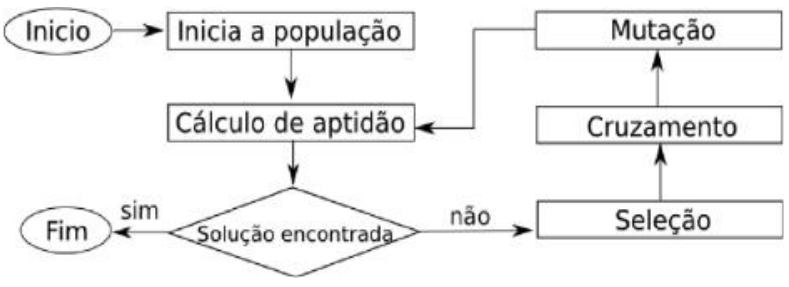

Figura 3: Ilustração do funcionamento dos algoritmos genéticos.

Baseado no exposto acima, os AGs buscam a solução para um problema de otimização por meio de um conjunto de soluções candidatas, explorando diferentes pontos do espaços de busca, sendo atribuído um fitness a cada solução do conjunto. A cada geração, soluções relativamente "boas" se reproduzem, enquanto que soluções relativamente "ruins" são eliminadas. Para fazer a distinção entre diferentes soluções, é empregada uma função de avaliação ou de adaptabilidade que simula o papel da pressão exercida pelo ambiente sobre o indivíduo.

Neste trabalho, a seleção dos animais para sugestão de acasalamento é feita por meio do algoritmo genético Nondominated Sorting Genetic Algorithm (NSGA-II) [3]. Foi 
utilizado o framework JMetal para a implentação do algoritmo [5].

\section{TRABALHOS RELACIONADOS}

O uso de algoritmos genéticos com o intuito de otimizar o encontro de soluções em um tempo mais factível já foi alvo de trabalhos no âmbito de Sistemas de Informação. Tourinho et al propuseram a aplicação de um algoritmo genético para otimizar as ações que devem ser executadas para o retorno de um conjunto de investimentos em um ano, dado um patamar aceitável de risco. Seu trabalho concluiu que o algoritmo proposto mostrou-se eficiente e eficaz, encontrando soluções superiores ao benchmark [23].

A aplicação de algoritmos evolutivos como propostas de soluções para o melhoramento genético vem sendo defendida por Mayer et al. Um de seus trabalhos comparou a eficiência e desempenho de quatro algoritmos evolutivos para otimização da característica relacionada à produção de carne. Foi destacado que o algoritmo evolução diferencial parece ser um dos mais eficientes e robustos para o problema [13].

Roberto Cavalheiro et al mostrou em seu trabalho a aplicação do algoritmo de evolução diferencial para otimização. As funções objetivos usadas foram compostas pelo mérito genético da futura progênie e pela coascendência média dos animais em reprodução. Nesse estudo foi desenvolvido um programa baseado em evolução diferencial para determinar contribuições genéticas ideais para a seleção de candidatos à reprodução. Para testes de viabilidade em aplicações práticas foi usado o conjunto de dados reais dos animais do rebanho Nelore, onde foram selecionados 100 touros e 500 fêmeas para reprodução (acasalamento). Uma das conclusões contidas no trabalho é que o programa desenvolvido mostrou-se computacionalmente eficiente e viável para aplicações práticas [2].

Os Mayer et al e Roberto Cavalheiro et al mostraram soluções para o melhoramento genético que utilizam o algoritmo de evolução diferencial com objetivos voltados para o melhoramento genético do gado de corte. Este trabalho se diferencia dos demais por ser um sistema web, que utiliza o algoritmo genético NSGA-II objetivando o melhoramento genético de caprinos e ovinos.

\section{ABORDAGEM PROPOSTA}

A abordagem proposta para gerar a sugestão de acasalamentos e com isso melhorar geneticamente um rebanho de caprinos e ovinos está representada na Figura 4.

A primeira fase da abordagem é a obtenção dos dados necessários para a seleção. Para isso, devem ser obtidas informações como: idade mínima para acasalamento de cada um dos sexos, a herdabilidade da característica a ser selecionada do animal e a quantidade de dias para o ajuste do peso. A segunda fase é a predição do parentesco de cada animal em relação ao resto do rebanho.

$\mathrm{Na}$ terceira fase (Seleção dos animais aptos a acasalar) é feita a seleção dos animais, que devem obedecer a três critérios de inclusão: estar vivo, ter a pesagem mínima ao desmame e ter a idade mínima para acasalar. Durante essa fase é feita a separação dos animais aptos em grupos de contemporâneos, o cálculo do DEP (Seção 2.2.2) e intervalo de geração (Seção 2.2.4) para cada animal apto e o cálculo do desvio padrão do rebanho para a característica peso.

A quarta fase (Otimização do melhoramento genético)

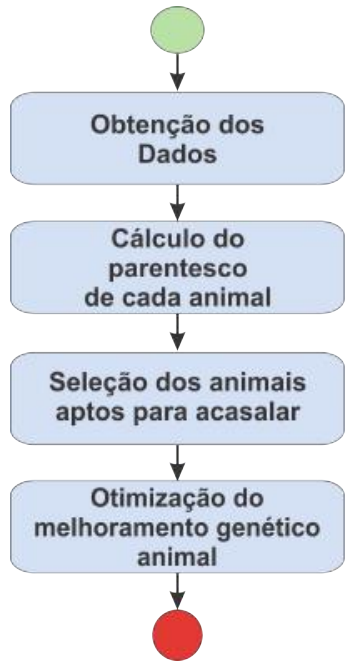

Figura 4: Abordagem Proposta.

pode ser executada de diversas formas. Em linhas gerais, é necessário invocar um método que consiga sugerir os melhores acasalamentos possíveis e que maximizem o ganho genético (Seção 2.2.4) e o DEP (Seção 2.2.2), além de minimizar a endogamia média da geração futura (Seção 2.2.3). Neste trabalho em específico foi utilizado um AG Multiobjetivo com o intuito de implementar as prescrições contidas na abordagem. O resultado final da abordagem é a sugestão de indicações de acasalamento que poderão gerar filhos com melhores valores genéticos e com pouco parentesco em relação ao rebanho.

\section{EXEMPLO DE APLICAÇÃO}

O sistema de melhoramento genético implementado no CAPRIOVI foi testado em ambiente real com dados provenientes do rebanho caprino da Universidade Federal do Piauí. O rebanho possui 193 animais. Na Tabela 1 é listado um excerto desse rebanho, que foi usado para a validação do sistema em um caso real.

$\mathrm{O}$ valor zero na Tabela 1 indica que animal é desconhecido, assim, o animal que tem a informação de pai ou mãe com valor zero não possui seus ancestrais definidos. "Peso" é o último peso cadastrado, e "Data P" corresponde à data da pesagem e "Estado" indica qual a situação atual do animal (vivo ou morto).

Um exemplo de parâmetros de entrada que deverão ser fornecidos para início do algoritmo de melhoramento genético no CAPRIOVI é:

- herdabilidade: 0,3 .

- Idade Mínima para acasalar do macho e fêmea: 1 ano de idade para ambos.

- Quantidade dias: 90. Neste parâmetro é definido para quantos dias será necessário projetar ou regredir o peso do animal.

Após as entradas dos parâmetros os cálculos necessários para o melhoramento são realizados de forma automatizada seguindo os passos descritos na abordagem. 


\begin{tabular}{|c|c|c|c|c|c|c|c|c|c|c|c|}
\hline Animal & Pai & Mãe & Sexo & Nascimento & Peso & Data P & Estado & GC & Int. de gerações (ano) & DEP & Endogamia \\
\hline 1 & 0 & 0 & $\mathrm{M}$ & $10 / 02 / 2006$ & & & MORTO & $2006 \mathrm{CM}$ & & & 1,0 \\
\hline 2 & 1 & 0 & $\mathrm{~F}$ & $10 / 01 / 2007$ & & & MORTO & $2007 \mathrm{CF}$ & & & 1,0 \\
\hline 3 & 0 & 2 & $\bar{M}$ & $10 / 12 / 2007$ & 20 & $09 / 03 / 2008$ & APTO & $2007 \mathrm{SM}$ & 2,78 & 0 & 1,0 \\
\hline 4 & 3 & 2 & $\mathrm{~F}$ & $10 / 11 / 2008$ & 17 & $08 / 02 / 2009$ & APTO & $2008 \mathrm{SF}$ & 1,39 & 0 & 1,25 \\
\hline 5 & 3 & 4 & $\bar{F}$ & $10 / 10 / 2009$ & 17 & $08 / 01 / 2010$ & APTO & $2009 \mathrm{SF}$ & 2,03 & $-0,075$ & 1,375 \\
\hline 6 & 1 & 2 & $\mathrm{~F}$ & $10 / 10 / 2009$ & 18 & $08 / 01 / 2010$ & APTO & $2009 \mathrm{SF}$ & 6,46 & 0,075 & 1,25 \\
\hline 7 & 3 & 4 & $\mathrm{~F}$ & $10 / 09 / 2010$ & 22 & $09 / 12 / 2010$ & APTO & $2010 \mathrm{SF}$ & 1,1 & 0 & 1,375 \\
\hline 8 & 3 & 7 & $\bar{M}$ & $10 / 10 / 2011$ & 23 & $08 / 01 / 2012$ & APTO & $2011 \mathrm{SM}$ & 4,44 & 0,225 & 1,438 \\
\hline 9 & 3 & 2 & $\mathrm{M}$ & $10 / 10 / 2011$ & 20 & $08 / 01 / 2012$ & APTO & 2011SM & 4,44 & $-0,225$ & 1,250 \\
\hline 10 & 1 & 5 & $\mathrm{~F}$ & $10 / 10 / 2011$ & 16 & $08 / 01 / 2012$ & APTO & $2011 \mathrm{SF}$ & 4,44 & 0 & 1,156 \\
\hline
\end{tabular}

Tabela 1: Dados do rebanho de caprinos da Instituição de Ensino Superior utilizada.

A segunda fase (Cálculo do parentesco de cada animal). O parentesco de cada animal é predito com o auxílio da Matriz de Parentesco (Seção 2.2.3), que é obtida com um algoritmo escrito na linguagem Fortran [6] para obter o parentesco de cada animal do rebanho. A escolha de Fortran se deu por conta de seu desempenho incomparável com outras linguagens. Para problemas envolvendo centenas de animais o seu tempo de execução era de mais de uma ordem de grandeza menor. Quanto maior essa quantidade, mais vantagem era obtida com o uso de Fortran.

A fase de seleção define quais animais serão aptos a prosseguir. No exemplo da Tabela 1, os animais 1 e 2 são excluídos na fase de seleção por estarem mortos. Os intervalos entre as gerações de cada animal são calculado. Tendo como exemplo o animal 4 que teve 2 filhos, o primeiro quando tinha 334,8 dias ou 0,93 anos de idade e o segundo quando tinha 669,6 dias ou 1,86 anos de idade, seu intervalo entre gerações será calculado:

$$
i_{f}=\frac{(1,86+0,93)}{2} \approx 1,39
$$

Em sequência é calculada a projeção do peso (Seção 2.2.1). Como exemplo será calculada abaixo a projeção para o animal 3.

$$
\text { Peso }=\frac{p_{i}}{t_{i}} * t_{\text {proj }} \approx \frac{20}{90} * 90 \approx 20
$$

Os animais da Tabela 1 foram descritos com as pesagens aos 90 dias, então todos os pesos já estão ajustados. Após todos os animais estarem com os pesos ajustados será dado continuidade ao processo calculando o desvio padrão da característica peso. Esse cálculo gera um desvio de 2,53.

Prosseguindo com o cálculo, os animais são separados em grupos contemporâneos - GC (Seção 2.2.2), que correspondem a um código de referência do grupo a que o animal pertence. Para a execução desse exemplo foi definido que os grupos seriam separados por ano de nascimento, estação do ano em que nasceram e sexo. Os animais que nasceram entre janeiro e maio foram referenciados como da estação chuvosa "C" e os nascidos entre junho e dezembro pertenceriam a estação seca "S". Esse padrão foi escolhido porque os animais testados eram provenientes da região Nordeste do país, que não possui todas as estações do ano bem definidas e com isso podem gerar viés na comparação entre animais. Para o sexo foram definidos "M" para macho e "F" para fêmea. Dessa forma, um animal com grupo "2006CM" é lido como um animal que nasceu no ano de 2006, é da estação chuvosa e é macho. Os grupos são necessários para o cálculo do DEP (Seção 2.2.2) de cada animal, pois ele precisa das médias dos pesos do GC a que o animal pertence. Por exemplo o grupo "2009SF" possui os animais 5 e 6, que possui média dos pe- sos 17,5 kg. A seguir é demonstrado o resto do cálculo para o DEP do animal 6.

$$
D E P=\frac{\left(p-\overline{p_{g c}}\right) * h^{2}}{2} \approx \frac{(18-17,5) * 0,3}{2} \approx 0,075
$$

Para finalizar a seleção, os animais devem ser separados pelo sexo. Nesse exemplo, a quantidade de animais aptos para acasalamento é de 5 fêmeas e 3 machos. Assim, será passado para o algoritmo genético duas listas de animais, da seguinte forma: uma lista contendo as fêmeas aptas a acasalar $(4,5,6,7,10)$ e outra lista contendo os machos aptos para acasalamento $(3,8,9)$.

O algoritmo genético é executado gerando populações de tamanho igual à quantidade de fêmeas aptas. Ou seja, o tamanho da saída é um vetor do mesmo tamanho da quantidade de fêmeas. Cada posição no vetor refere-se a uma das fêmeas aptas para acasalamento. Um valor específico em uma posição do vetor indica o macho que a fêmea deve acasalar ou se a fêmea não foi sugerida nessa solução. Cada item no vetor varia de " 1 " a "n-1", onde "n" corresponde a quantidade de machos aptos. Um exemplo de resultado é demonstrado abaixo.

$$
\begin{gathered}
\text { Machos: }[3,8,9] \\
\text { Fêmeas: }[4,5,6,7,10] \\
\text { Sugestão : }[2.0,-1.0,-1.0,1.0,2.0]
\end{gathered}
$$

Cada item do vetor "Sugestão" representa uma sugestão de acasalamento. Por exemplo, a primeira posição representa a primeira fêmea, que é o animal de número 4 . O valor 2 nesta posição do vetor Sugestão indica que o animal sugerido para acasalamento significa que a Fêmea 4 vai acasalar com o macho referenciado na posição 2 do vetor, que é

\begin{tabular}{|c|c|c|c|}
\hline Macho & Fêmea & DEP & Endogamia \\
\hline 9 & 4 & $-0,112$ & 1,375 \\
\hline-1 & 5 & & \\
\hline-1 & 6 & & \\
\hline 8 & 7 & 0,112 & 1,5625 \\
\hline 9 & 10 & $-0,112$ & 1,2813 \\
\hline \multicolumn{2}{|c|}{ Médias: } & $-0,0375$ & 1,40625 \\
\hline
\end{tabular}
o animal de número 9. Por convenção o "-1" no vetor indica a não seleção de uma fêmea para o acasalamento. O quarto número no vetor "Sugestão" indica que a quarta fêmea no rebanho (Animal 7) deverá acasalar com o segundo macho, que é o Animal 8.

Tabela 2: População avaliada.

$\mathrm{Na}$ Tabela 2 são mostrados os casais e as suas respectivas contribuições genéticas para o melhoramento. A DEP é uma média dos diferenciais que estão na Tabela 1 para estes casais. A endogamia é um valor calculado com base na 
Equação 3 e utilizando os dados da Figura 2 (Seção 2.2.3). Para o casal 9 e 4 temos que:

$$
\text { End }=1+\frac{M_{[9,4]}}{2} \approx 1+\frac{0,75}{2} \approx 1,375
$$

A intensidade de seleção é uma relação da proporção de animais selecionados. Para a população em questão temos que a intensidade de seleção para o macho é 0,555 e a intensidade para a fêmea é de 0,664 .

No passo seguinte é calculado o ganho genético da população, que é calculado utilizando a equação 4 (Seção 2.2.4).

$\Delta G=\frac{\overline{i_{m}}+\overline{i_{f}}}{\overline{l_{m}}+\overline{l_{f}}} * h^{2} * \sigma_{p} \approx \frac{0,555+0,644}{4,44+2,31} * 0,3 * 2,53 \approx 0,13$

O resultado apresentado mostra que se os animais da Tabela 2 acasalassem seguindo as sugestões indicadas, seus filhos teriam em média um ganho genético de $0,13 \mathrm{~kg}$ ou 130 gramas para a característica peso, aos 90 dias.

O algoritmo usado na atual versão do CAPRIOVI testará várias populações, calculando as funções objetivos e priorizando as populações para que se chegue a um resultado interessante, porém, sem explorar todo o conjunto de possíveis resultados. Ao final da execução do módulo de melhoramento genético do CAPRIOVI, é apresentado ao criador as melhores opções de acasalamento encontradas. Um exemplo de saída é exibida na Tabela 3 .

\begin{tabular}{|c|c|c|c|}
\hline \multicolumn{3}{|c|}{ Propostas } & 1 \\
\hline \multicolumn{3}{|c|}{ Ganho genético } & $0,5 \mathrm{~kg}$ \\
\hline \multicolumn{3}{|c|}{ DEP Médio } & $0,0 \mathrm{~kg}$ \\
\hline \multicolumn{3}{|c|}{ Endogamia Média } & 1,4375 \\
\hline PAI & MAE & DEP Esperado & Endogamia \\
\hline 3 & 7 & 0 & 1,4375 \\
\hline
\end{tabular}

Tabela 3: As propostas de acasalamento

Em resumo, para o rebanho apresentado na Tabela 1, as melhores propostas de acasalamentos tem como pais e mães para próxima geração os resultados apresentados na Tabela 3 , com uma predição máxima calculada de ganho de peso de aproximadamente $0,5 \mathrm{~kg}$ para a característica peso aos 90 dias e com um parentesco com $43,75 \%$ do rebanho.

O rebanho apresentado na Tabela 1 é de caprinos, mas a mesma abordagem pode ser aplicada a um rebanho de ovinos, pois caprinos e ovinos apesar de serem espécies diferentes têm comportamentos parecido e a modelagem estatística entre as duas espécies praticamente não mudam ao se estudar a mesma característica.

Foi realizada a aplicação do CAPRIOVI no rebanho da Instituição de Ensino Superior (IES) parceira no projeto, que possui 193 animais. Após a seleção dos animais restaram 14 machos e 79 fêmeas aptas para acasalamento. Esse grupo gera um conjunto de $15^{79}$ combinações. Encontrar as melhores sugestões de acasalamento sem o apoio da Inteligência Computacional inviabiliza a melhoria genética.

Com o uso do CAPRIOVI, a sugestão de acasalamentos para melhoramento genético no rebanho da IES parceira é produzida em segundos. São exemplos de sugestões de acasalamento os pares listados na Tabela 4. Tais propostas foram analisadas por especialistas e comparadas com propostas geradas de forma manual por alguns desses especialistas, tendo sido considerada superior em termo de possibilidade de melhoramento genético. Foi encontrado o melhor valor possível na lista de sugestões de acasalamento. Vários acasalamentos foram realizados e os filhotes estão sendo acompanhados para se gerar relatórios mais aprofundados sobre a melhoria genética obtida.

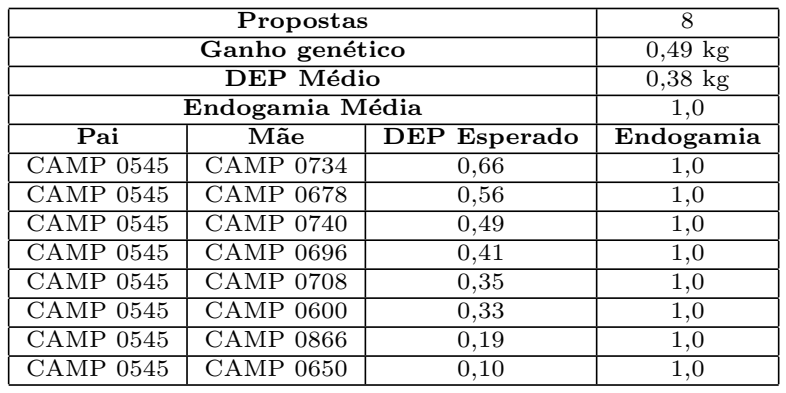

Tabela 4: As propostas de acasalamento para o rebanho Campinas (IES parceira).

\section{CONCLUSÃO}

Este trabalho apresenta um Sistema de Informação cujo objetivo é auxiliar criadores de ovinos e caprinos no controle zootécnico do seu rebanho, além de melhorar a qualidade dos seus animais, por meio da aplicações de técnicas de melhoramento genético. No CAPRIOVI existe um módulo de melhoramento genético que permite gerar as melhores sugestões de acasalamento, a partir do emprego de uma técnica de melhoramento animal combinada com o uso de um algoritmo de Inteligência Computacional baseado em algoritmos genéticos.

É muito importante para os criadores da ovinocaprinocultura a aplicação de técnicas de melhoramento genético em seus animais. O melhoramento proporciona um aumento na qualidade genética, pois propõe animais com alto ganho genético e com maior variabilidade genética, pois evita gerações endogâmicas. Isso significa animais com maior valor agregado e com isso uma chance maior de abastecimento do mercado nacional sem a necessidade de importação desse item de consumo.

Para que pequenos criadores realizem alguma atividade de melhoramento genético é necessária a contratação de especialistas, que não são tão abundantes no mercado. Uma avaliação por especialista normalmente dura muitos dias, em função da complexidade do assunto. Mesmo para um pequeno exemplo, como o apresentado neste trabalho, contendo apenas 10 animais, exigiria de um especialista algo em torno de 1 hora de trabalho, ainda que ele tenha um conjunto de planilhas pré-ajustadas para se realizar a tarefa. Com o CAPRIOVI, além do criador contar com um sistema automatizado para escrituração zootécnica, ele pode executar o módulo de melhoramento genético e receber sugestões de acasalamento em segundos. Tudo isso executado de qualquer lugar e em qualquer hora.

O CAPRIOVI já está sendo utilizado em caráter aplicado em um rebanho de uma instituição de ensino superior. Os acasalamentos realizados com apoio do software já produziram descendentes que estão sendo analisados para uma melhor avaliação das técnicas implementadas e com isso permitir a sugestão de mais melhorias no trabalho desenvolvido. As sugestões elencadas pelo CAPRIOVI foram melho- 
res que as sugestões dos especialistas, visto que a quantidade de combinações possíveis em tal rebanho era muito grande, inviabilizando o cálculo manual.

Um trabalho futuro em andamento é incluir no sistema um módulo para melhoria genética relacionada a outra característica muito importante no agronegócio: a produção de leite. Para isso, estão sendo realizados estudos para levantamento das técnicas que representam o estado da arte sobre o tema para sua posterior introdução no sistema.

\section{REFERÊNCIAS}

[1] CANCHIM. O que é dep? http://www . abccan.com.br/canchim/index.php/ sumario-de-touros/o-que-e-dep.html, 2015. último acesso em 10/06/2015.

[2] R. Carvalheiro, S. A. d. Queiroz, and B. Kinghorn. Optimum contribution selection using differential evolution. Revista Brasileira de Zootecnia, 39(7):1429-1436, 2010.

[3] K. Deb, A. Pratap, S. Agarwal, and T. Meyarivan. A fast and elitist multiobjective genetic algorithm: NSGA-II. IEEE Transactions on Evolutionary Computation, 6(2):182-197, 2002.

[4] L. Dempfle. Problems in the use of the relationship matrix in animal breeding. In Advances in statistical methods for genetic improvement of livestock, pages 454-473. Springer, 1990.

[5] J. J. Durillo, A. J. Nebro, and E. Alba. The jmetal framework for multi-objective optimization: Design and architecture. In Evolutionary Computation (CEC), 2010 IEEE Congress on, pages 1-8. IEEE, 2010.

[6] T. Ellis, I. Philips, and T. Lahey. Fortran 90 programming. International computer science series Show all parts in this series, 1994.

[7] A. P. Engelbrecht. Computational intelligence: an introduction. John Wiley \& Sons, 2007.

[8] K. Euclides Filho. Melhoramento genético animal no Brasil: fundamentos, história e importância. Embrapa Gado de Corte, 1999.

[9] K. EUCLIDES FILHO. Melhoramento genético animal no brasil: fundamentos, história e importância, 2000. Embrapa-CNPGC. Disponivel em: http://www. cnpgc. embrapa. br/publicacoes/doc/doc75/index. html Acesso em 10/06/2015, 4(4), 2011.

[10] D. E. Goldberg et al. Genetic algorithms in search optimization and machine learning, volume 412 Addison-wesley Reading Menlo Park, 1989.

[11] C. Henderson. A simple method for computing the inverse of a numerator relationship matrix used in prediction of breeding values. Biometrics, pages $69-83$, 1976.

[12] IBGE. Pesquisa pecuária municipal. http://www.sidra.ibge.gov.br/, 2010. último acesso em $10 / 02 / 2015$.

[13] D. Mayer, B. Kinghorn, and A. Archer. Differential evolution-an easy and efficient evolutionary algorithm for model optimisation. Agricultural Systems, 83(3):315-328, 2005.

[14] M. Mi, A. Chapman, and W. Tyler. Effects of mating system on production traits in dairy cattle. Journal of dairy science, 48(1):77-84, 1965.
[15] Z. Michalewicz. Genetic algorithms + data structures= evolution programs. Springer Science \& Business Media, 2013.

[16] B. Nowicki. The influence of inbreeding on the utility value of black pied lowland cows. In Anim. Breed. Abstr, volume 32, page 966, 1963.

[17] T. PIRLEA, S. ILEA, et al. Effect of different inbreeding intensities on some production characters in cattle. Lucrarile stiintifice ale Institutul de cercetari zootehnice, 27:113-121, 1970.

[18] R. Quaas. Computing the diagonal elements and inverse of a large numerator relationship matrix. Biometrics, pages 949-953, 1976.

[19] N. RURAL. A caprinovinocultura no nordeste brasileiro. http://www.nordesterural.com.br/ nordesterural/matler. asp?newsId=1916, 2004. último acesso em maio de 2011.

[20] L. M. M. SANTOS. Ação do vírus da artrite encefalite caprina (caev) e agentes bacterianos na contagem de células somáticas em leite de rebanhos caprinos. Master's thesis, Universidade Federal Fluminense UFF, 2014.

[21] M. F. d. A. SOUSA. Sistema de melhoramento genético - software de controle zootécnico e genético de caprinos e ovinos, 2011.

[22] H. STREWE. Inbreeding as a test of genetic health in cattle. In Dairy Sci. Abstr, volume 36, page 3572, 1974.

[23] R. F. Tourinho, A. C. de Oliveira, and R. d. M. S. Veras. Um algoritmo genético para seleção de portfólio de investimentos com restrições de cardinalidade e lotes-padrão. Simpósio Brasileiro de Sistemas de Informação, 2013.

[24] F. Vargas Júnior, A. Leão, M. Longo, J. d. S. Osório, M. Osório, and A. Leonardo. A situação dos pequenos ruminantes na américa latina: Mercaod e potencial futuro. América latina, 1990:2000, 1980. 